(2)

\title{
19-Fluorine nuclear magnetic resonance chemical shift variability in trifluoroacetyl species
}

\author{
This article was published in the following Dove Press journal: \\ Reports in Organic Chemistry \\ 19 February 2013 \\ Number of times this article has been viewed
}

\section{Joseph C Sloop}

School of Science and Technology, Georgia Gwinnett College, Lawrenceville, GA, USA
Correspondence: Joseph C Sloop School of Science and Technology, Georgia Gwinnett College, 1000 University Center Lane, Lawrenceville, GA 30043, USA

$\mathrm{Tel}+\mid 678485502$ I

Fax + I 6784075938

Email jsloop@ggc.edu
Abstract: This review examines the variability of chemical shifts observed in 19-fluorine $\left({ }^{19} \mathrm{~F}\right)$ nuclear magnetic resonance spectra for the trifluoroacetyl (TFA) functional group. The range of ${ }^{19} \mathrm{~F}$ chemical shifts reported spectra for the TFA group varies generally from -85 to $-67 \mathrm{ppm}$ relative to $\mathrm{CFCl}_{3}$. The literature revealed several factors that impact chemical shifts of the TFA moiety - substrate topology, electronic environment, solvent polarity, and concentration effects. Often these effects conspire to cause deshielding of the TFA group by up to $15 \mathrm{ppm}$. These factors will be examined for a series of TFA-functionalized acyclic, cyclic, aromatic, and heterocyclic molecules.

Keywords: ${ }^{19} \mathrm{~F}$ NMR, chemical shift, shielding, trifluoroacetyl group, fluorinated diketones, triketones

Fluorinated molecules have found wide application in many areas, including the pharmaceutical and agrochemical industries and as precursors to surfactants, polymers, and flame retardants. ${ }^{1-3}$ The properties exhibited by molecules incorporating fluorine often include tuned lipophilicity or lipophobicity as well as enhanced bioactivity. ${ }^{4-7}$ As a biochemical marker and precursor to heterocyclic species, the trifluoroacetyl (TFA) group has gained exceptional versatility; its incorporation into molecular architecture is effected via its use as a synthon or through acetylation strategies.

19-Fluorine $\left({ }^{19} \mathrm{~F}\right)$ nuclear magnetic resonance (NMR) has become widely used as a means of verifying successful introductions of specific TFA moieties in organic molecules. ${ }^{8,9}$ In the pivotal work Guide to Fluorine NMR for Organic Chemists, Dolbier described the use of ${ }^{19} \mathrm{~F}$ NMR spectroscopy as a tool for structural elucidation and characterization, especially when combined with other spectroscopic methods. ${ }^{10}$ An examination of the scientific literature showed that while the variation demonstrated in the chemical shifts exhibited by the TFA group can be of tremendous assistance in elucidating the molecular topology of fluorinated materials, factors, such as electronic environment, solvent polarity, and concentration, often modulate ${ }^{19} \mathrm{~F}$ NMR resonance frequencies observed for the TFA group. ${ }^{11-13}$

This review examines ${ }^{19} \mathrm{~F}$ NMR chemical shift variability for nine classes of molecules that contain TFA groups: isolated $\alpha, \alpha, \alpha$-trifluorocarbonyl species, $\alpha, \beta$-unsaturated TFA species, acyclic trifluoromethyl- $\beta$-dicarbonyls, 2-trifluoroacetylcycloalkanones, fused-ring trifluoroacetylated ketones, $\alpha, \alpha, \alpha$-trifluoromethyl-1,3,5-triketones, cyclic trifluoroacetylated triketones, trifluoroacetylated aromatics, and trifluoroacetylated heterocycles. The species chosen in this study are of broad importance in the field of organic synthesis as building blocks to highly functionalized, industrially, 
and medicinally valuable molecules that incorporate the trifluoromethyl $\left(\mathrm{CF}_{3}\right)$ moiety. The effects of substrate topology, electronic environment, the influence of solvent especially when related to modulation of tautomeric equilibria and concentration, will be discussed for each TFA class.

\section{Factors influencing ${ }^{19} \mathrm{~F}$ NMR chemical shifts of the TFA functional group Shielding of the fluorine nucleus - general considerations}

The chemical shifts exhibited by $\mathrm{CF}_{3}$ group-containing molecules in the ${ }^{19} \mathrm{~F}$ NMR range from $-5.1 \mathrm{ppm}$ (relative to $\mathrm{CFCl}_{3}$ ) in the case of $\mathrm{CF}_{3} \mathrm{I}$ to more than $-84 \mathrm{ppm}$ for hexafluoroacetone, $\left(\mathrm{CF}_{3}\right)_{2} \mathrm{C}=\mathrm{O}$ (Figure 1). ${ }^{10}$

An important aspect of ${ }^{19} \mathrm{~F}$ NMR chemical shift interpretation for the $-\mathrm{CF}_{3}$ group involves an understanding of the effect of shielding on the fluorine nucleus. As Figure 1 shows, as field strength increases, shielding of the $\mathrm{CF}_{3}$ group increases. This is perhaps not intuitive since, for most persons who are familiar with proton NMR, the reverse is observed.

Of course, there is an explanation for this difference. ${ }^{10}$ For NMR active nuclei, the effective magnetic field experienced by the nucleus $\left(\mathrm{B}_{e f f}\right)$ is given by Equation 1:

$$
\mathrm{B}_{e f f}=\mathrm{B}_{\mathrm{o}}-\sigma \mathrm{B}_{\mathrm{o}}
$$

where $\mathrm{B}_{\mathrm{o}}$ is the applied magnetic field and $\sigma$ is the shielding constant. The shielding constant arises from the contributions of the terms shown in Equation 2:

$$
\sigma=\sigma_{\text {dia }}+\sigma_{\text {para }}+\sigma_{\mathrm{i}}
$$

where $\sigma_{\text {dia }}$ is defined as the opposing field generated by the applied magnetic field's effect on the atom's electron cloud,

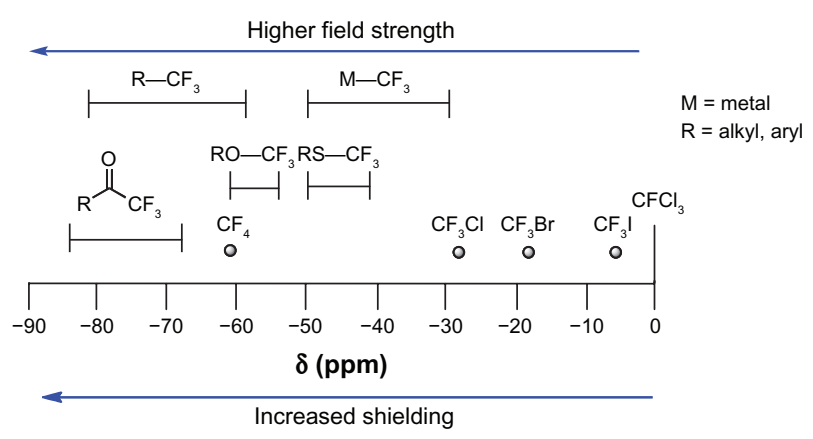

Figure I ${ }^{19} \mathrm{~F}$ NMR chemical shift ranges for $\mathrm{CF}_{3}$-containing molecules.

Abbreviations: ${ }^{19} \mathrm{~F} \mathrm{NMR}$, 19-fluorine nuclear magnetic resonance; $\mathrm{CF}_{3}$, trifluoromethyl; M, metal; R, alkyl, aryl. $\sigma_{\text {para }}$ is the contribution to shielding resulting from the applied magnetic field's interaction with the atom's p orbital electrons, and $\sigma_{\mathrm{i}}$ is the contribution arising from the influence that neighboring groups have on the atom of interest. Whereas for the hydrogen atom that contains a lone s orbital electron, the principal contribution to shielding is $\sigma_{\text {dia }} ; \sigma_{\text {para }}$ dominates in the case of fluorine due to the large number of $p$ electrons present. The $\sigma_{\text {para }}$ contribution is opposite in its shielding effect from that of $\sigma_{\text {dia }}$, hence the typical deshielding effect observed in proton spectra does not apply to ${ }^{19} \mathrm{~F}$ spectra. Presented below are factors that impact the chemical shifts observed specifically for the TFA group. These include substrate topology, electronic environment, solvent polarity and concentration effects.

\section{Substrate topology}

As Figure 1 shows, the carbonyl moiety of the TFA group shields $-\mathrm{CF}_{3}$ fluorines to a greater extent than other functionalities. Certain TFA groups attached to molecular residues that extend conjugation or permit tautomerization can, however, be deshielded by as much as $15 \mathrm{ppm} .{ }^{8,9,12-14}$

As the Figure 2 shows, $\alpha, \alpha, \alpha$-trifluoro- $\beta$-diketone tautomerization from the diketo form $\left(\pi_{\mathrm{Csp2-Osp2}}\right)$ to a keto-enol form $\left(\pi_{\text {Csp2-Csp2 }}\right)$ results in a shift of the ${ }^{19} \mathrm{~F}$ NMR resonance for the $-\mathrm{CF}_{3}$ group to a lower field as a result of diminished shielding by the $\mathrm{C}=\mathrm{C}$ enolic topology. To illustrate this trend, the ${ }^{19} \mathrm{~F}$ NMR spectra of 1,3-ditrifluoroacetyl-2-indanone, 2-trifluoroacetyl-1-tetralone and 3-trifluoroacetyl-2-naphthol (Figure 3) show how keto-enolic and ring-size substrate topology influences chemical shift. As indicated, the smaller ring size and exocyclic keto-enol structure in 1,3ditrifluoroacetyl-2-indanone lead to greater $-\mathrm{CF}_{3}$ deshielding (-68.5 ppm) than the endocyclic keto-enol TFA-substituted tetralone (-72.1 ppm) and aromatic TFA-substituted naphthol (-74.3 ppm) examples. The aromatic ring "locks" the $\mathrm{COCF}_{3}$ group into an endocyclic keto-enol configuration, shielding the fluorines further. A similar effect is also observed in conjugated $\mathrm{CF}_{3}$ ketones, such as the trifluoroacetophenones, where chemical shifts can vary up to $10 \mathrm{ppm}$.

\section{Electronic environment}

Shielding diminution due to resonance effects likewise influences the TFA group. ${ }^{9}{ }^{12}$ This phenomenon is exhibited by the carboxylic acid derivative family of compounds and can result in deshielding of the fluorine nucleus by $\sim 6-8 \mathrm{ppm}$ relative to chemical shifts observed for aliphatic $\mathrm{CF}_{3}$ ketones. In Figure 4, the contributors to the overall resonance hybrid highlight a redistribution of electron density that serves to 


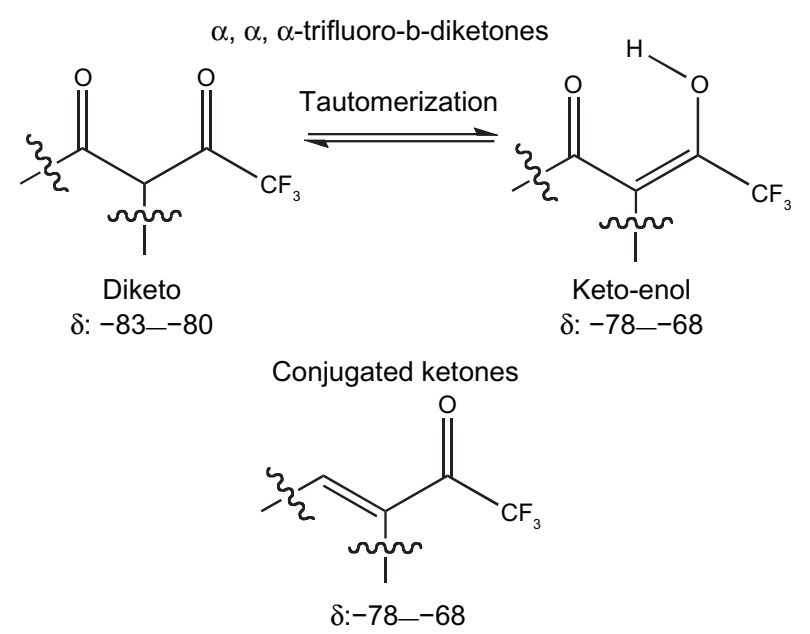

Figure 2 Shielding effects of substrate topology.

Abbreviation: $\mathrm{CF}_{3}$, trifluoromethyl. mitigate the shielding effect of the carbonyl on the fluorine atoms of the $\mathrm{CF}_{3}$ group.

\section{Solvent polarity}

In general, solvent polarity impacts chemical shifts in the ${ }^{19} \mathrm{~F}$ NMR by no more than $\sim 2 \mathrm{ppm} .{ }^{10}$ In most situations, shielding decreases as solvent polarity increases, with highly polar aprotic solvents, such as dimethyl sulfoxide (DMSO) and dimethyl formamide (DMF), having the largest deshielding effect. ${ }^{10}$ One may rationalize this phenomenon on the basis of increased solvent clustering around the highly electron-withdrawing $-\mathrm{CF}_{3}$ group, ameliorating the shielding effect of neighboring functional groups.

An exception to the rather limited effect noted above occurs when a change in solvent polarity influences
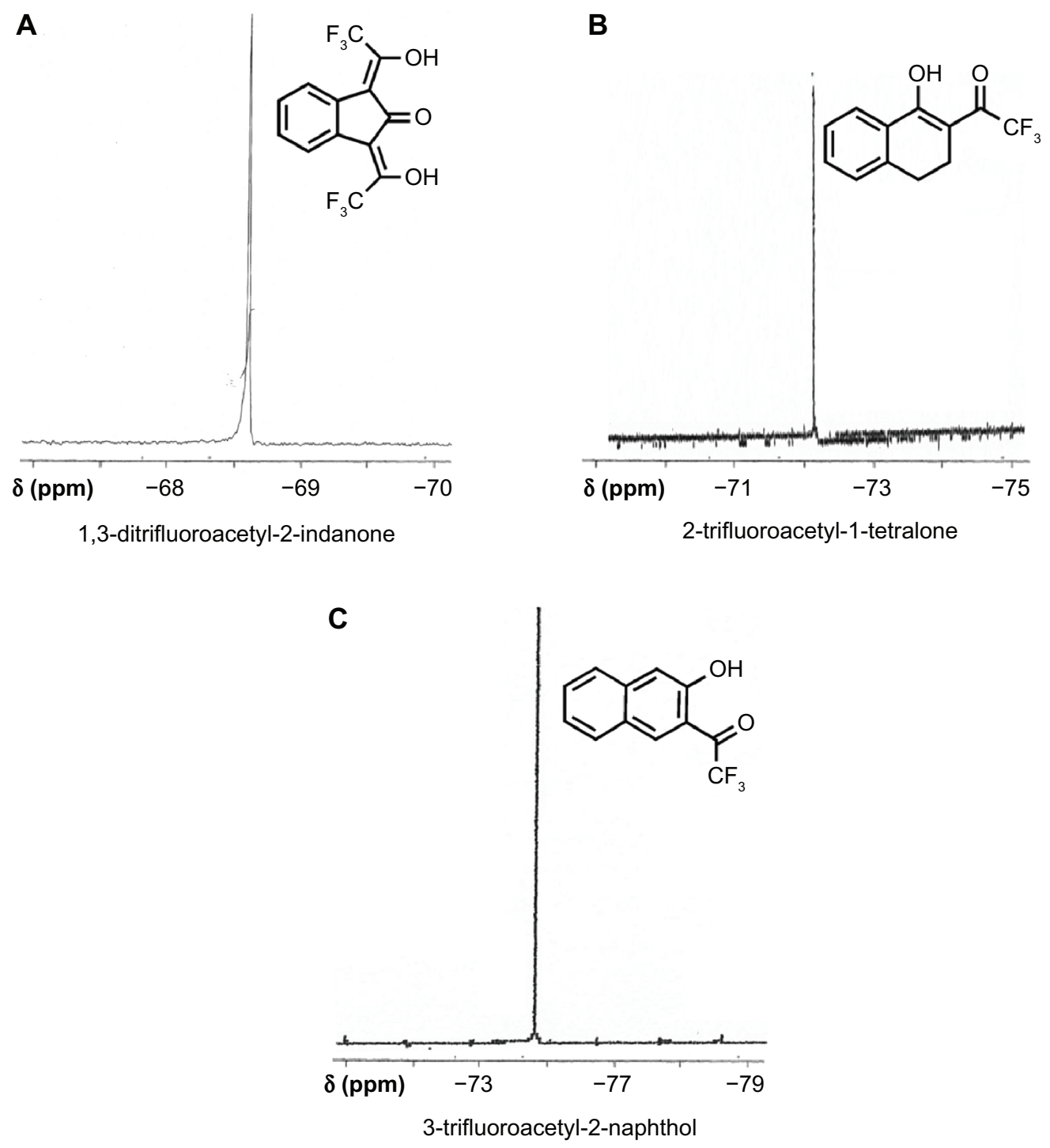

Figure $3{ }^{19} \mathrm{~F}$ NMR spectra demonstrating deshielding effects of substrate topology. Abbreviation: $\mathrm{CF}_{3}$, trifluoromethyl. 
Carboxylic acid derivative resonance forms<smiles>[Y]C(CC)(CCC)C(F)(F)F</smiles>

Carboxylic acid derivative resonance hybrid<smiles>[Y]OCC(=O)C(C)=[V]C(=O)O</smiles>

Figure 4 Resonance diminution of shielding.

substrate topology. For example, in the case of $\beta$-dicarbonyls discussed earlier, polar, aprotic, and polar protic solvents can shift the tautomeric equilibrium in the direction of the more shielded diketo form, a chemical shift difference of 4-8 ppm. ${ }^{15}$ Polar protic solvents, such as ethanol, disrupt the intramolecular hydrogen bonding found in $\beta$-dicarbonyls, resulting in a shift in the tautomeric equilibrium toward the diketo form. ${ }^{9}$ This effect is demonstrated in the NMR spectra of 1,1,1-trifluoro-2,4-pentanedione (Figure 5) in solvents of varying polarity.
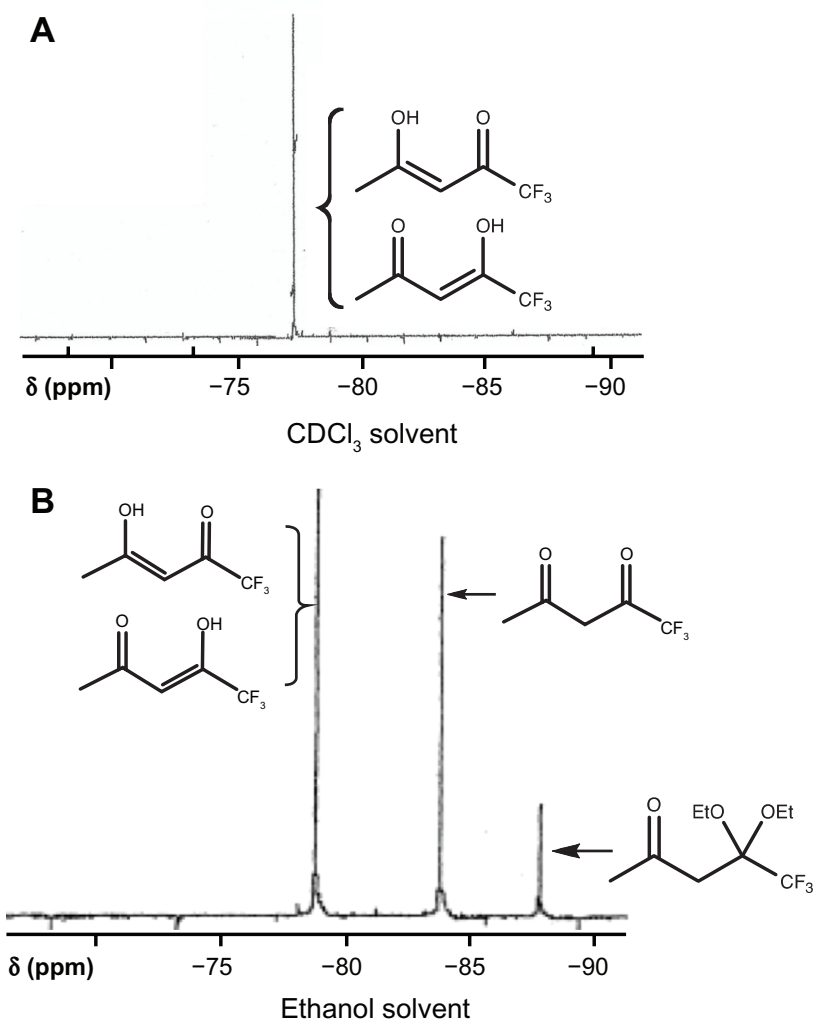

Figure $5{ }^{19} \mathrm{~F}$ NMR spectra of I, I, I-trifluoro-2,4-pentanedione demonstrating deshielding effects of $\mathrm{CDCl}_{3}(\mathbf{A})$ and ethanol (B) solvent polarity.

Abbreviations: ${ }^{19} \mathrm{~F}$ NMR, 19-fluorine nuclear magnetic resonance; $\mathrm{CF}_{3}$, trifluoromethyl.

\section{Concentration effects}

In some limited situations, concentration can alter tautomeric equilibria exhibited by the $\beta$-diketone classes of TFA-bearing molecules. As Reichardt and other researchers noted, highly concentrated solutions of $\beta$-diketones favor a tautomeric shift toward the diketo form (Figure 2). ${ }^{12,15}$ In a few cases where the subject compounds investigated are neat liquids, ${ }^{19} \mathrm{~F}$ NMR studies showed that small proportions of the diketo tautomer (usually $<10 \%$ ) are present in addition to the keto-enol form. ${ }^{8}$ This effect is linked to substrate topology and is observed more commonly in cyclic examples than in acyclic cases. For example, variable concentration studies of 4,4,4-trifluoro-1-phenyl-1,3-butanedione $(0.0016 \mathrm{M}-0.20 \mathrm{M}$, neat liquid) reveal no chemical shift variability in the ${ }^{19} \mathrm{~F}$ NMR spectra, ${ }^{12}$ while neat liquid ${ }^{19} \mathrm{~F}$ NMR studies of 2-trifluoroacetylcyclopentan-1-one, 2-trifluoroacetylcyclohexan-1-one, 2-trifluoroacetylcycloheptan-1-one, and 2-trifluoroacetylcyclooctan-1-one show both diketo and keto-enol forms present, with the diketo form being present in less than $10 \%$ proportion to the keto-enol form. ${ }^{8}$

\section{Temperature effects}

While temperature changes are noted to impact chemical shifts of complex biomolecules by altering the three-dimensional nature of the molecules, ${ }^{16}$ simple TFA-bearing molecules of interest in this review do not show any chemical shift variability. Variable temperature studies performed on 1,1,1-trifluoro-2,4pentanedione ( $253 \mathrm{~K}$ to $298 \mathrm{~K}$ ) and 4,4,4-trifluoro-1-phenyl-1,3butanedione ( $298 \mathrm{~K}$ to $348 \mathrm{~K}$ ) show no chemical shift change in their ${ }^{19} \mathrm{~F}$ NMR spectra as a function of temperature. ${ }^{9,12}$

\section{Discussion and analysis of chemical shift variations for TFA-bearing molecules}

We begin our review by considering the range of ${ }^{19} \mathrm{~F}$ chemical shift values associated with the simplest examples of the TFA functionality, those bearing TFA groups that are isolated from functional groups that exhibit conjugating effects. This will be followed by an examination of more complex trifluoroacetylated molecules. For direct comparative purposes, all fluorine NMR chemical shifts $(\delta)$ are reported in ppm relative to $\mathrm{CFCl}_{3}$.

\section{Isolated $\alpha, \alpha, \alpha$-trifluorocarbonyl species}

Carbonyl species in this group and shown in Figure 6 include ketones, aldehydes, pyruvates, and carboxylic acid derivatives. As can be seen, the $\mathrm{CF}_{3}$ group in aldehydes and ketones is shielded relative to that of the pyruvates and carboxylic acid derivatives. In the case of the pyruvate family, the $\alpha$-carbonyl 


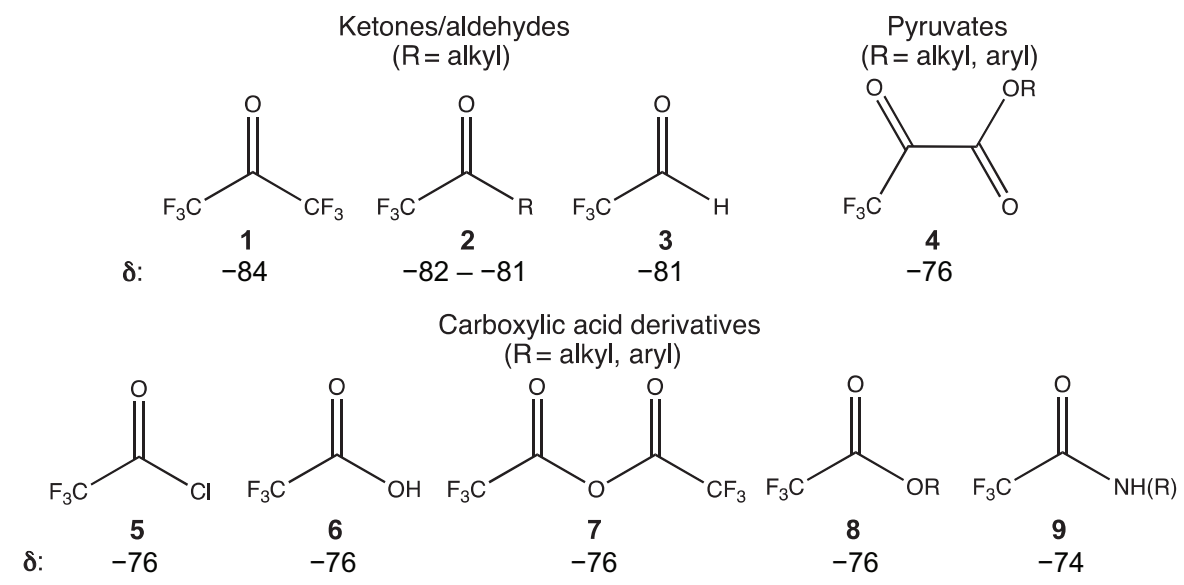

Figure 6 Isolated $\alpha, \alpha, \alpha$-trifluorocarbonyl species. Abbreviations: $\mathrm{CF}_{3}$, trifluoromethyl; $\mathrm{R}$, alkyl, aryl.

residue can be considered a de facto conjugating group to the TFA functionality, having a net deshielding effect on the $\mathrm{CF}_{3}$ ${ }^{19} \mathrm{~F}$ chemical shift. For the carboxylic acid derivatives, the chemical shifts observed are largely a function of resonance deshielding. One notes that with the improved donor capacity of the nitrogen, the deshielding effect is enhanced, albeit to a small degree. Solvent and concentration effects, if any, would be small for these examples. ${ }^{10,15}$

\section{$\alpha, \beta$-Unsaturated trifluoromethyl ketones}

The presence of an alkenyl unit in conjugation with the TFA group (compound series 10) deshields the $-\mathrm{CF}_{3}$ group relative to isolated $\mathrm{CF}_{3}$ ketones (compound series 2) (Figure 7). This effect is smaller than the resonance deshielding observed for the trifluoroacetic acid derivatives (series 5-9), with chemical shifts for compound series 10 differing by only $\sim 1 \mathrm{ppm} .{ }^{17}$ Even when $\mathrm{Y}=\mathrm{Ph}$, the additional conjugation afforded by the benzene ring does not serve to deshield the $-\mathrm{CF}_{3}$ group to any greater extent $(\delta=-78.1 \mathrm{ppm})$. Solvent and concentration effects on the ${ }^{19} \mathrm{~F}$ NMR chemical shifts would be minimal for this series of compounds.

\section{Acyclic trifluoromethyl- $\beta$-dicarbonyls}

This class of TFA-containing compounds has been thoroughly investigated. As shown in Figure 8, the

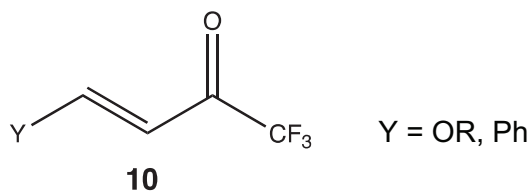

$\delta: \quad \quad-77.7--78.6$

Figure $7 \alpha, \beta$-Unsaturated trifluoromethyl ketones. Abbreviations: $\mathrm{CF}_{3}$, trifluoromethyl; $\mathrm{OR}$, alkoxy; $\mathrm{Ph}$, phenyl. $\beta$-diketones (compound series 11) show a marked preference for the keto-enol tautomeric forms $\mathrm{a}$ and $\mathrm{b}$ in nonpolar solvents. ${ }^{9}$ For cases where $\mathrm{R}=$ alkyl groups, the $\mathrm{a} \leftrightharpoons \mathrm{b}$ dynamic equilibrium is near unity and only one ${ }^{19} \mathrm{~F}$ NMR resonance for the $-\mathrm{CF}_{3}$ group is observed, usually ranging from -78 to $-76 \mathrm{ppm}$. In polar aprotic and polar, protic solvents the equilibrium can shift in certain cases toward the diketo form, but the keto-enol forms remain dominant. When $\mathrm{R}=$ aryl, recent evidence suggests that keto-enol form $\mathrm{b}$ predominates because of extended conjugation afforded by the aromatic ring, and a single ${ }^{19} \mathrm{~F}$ NMR resonance for the $-\mathrm{CF}_{3}$ group is observed, again ranging from -78 to $-76 \mathrm{ppm}$. Solution studies of selected trifluoromethyl- $\beta$-diketones $(\mathrm{R}=$ aryl) have found little evidence of a discernible concentration effect over a wide range of concentrations. ${ }^{12}$

Conversely, in the cases of compound series 12 and 13, the only form observed is the diketo form. For series 12, this preference is rationalized on the basis of Frontier Molecular Orbital theory. ${ }^{18}$ The presence of a single 2-fluoro substituent destabilizes the keto-enol form, leading to observations of the more highly shielded diketo tautomer, which has chemical shifts above $-80 \mathrm{ppm} .{ }^{9}$ This preference holds true in all examined solvent systems, whether nonpolar, polar aprotic, and polar protic. It also appears to be independent of concentration. For compound series 13, only the diketo form is possible, yielding chemical shift values $>-80 \mathrm{ppm}$ as well. ${ }^{12}$

The $\beta$-keto ester and $\beta$-ketoamide series 14 enolizes in the direction of the $-\mathrm{CF}_{3}$ group, producing an enol form reminiscent of the keto-enol form in series 11. As expected, this enolization deshields the $-\mathrm{CF}_{3}$ group; chemical shift values range from -77 to $-75 \mathrm{ppm} .{ }^{10}$ 


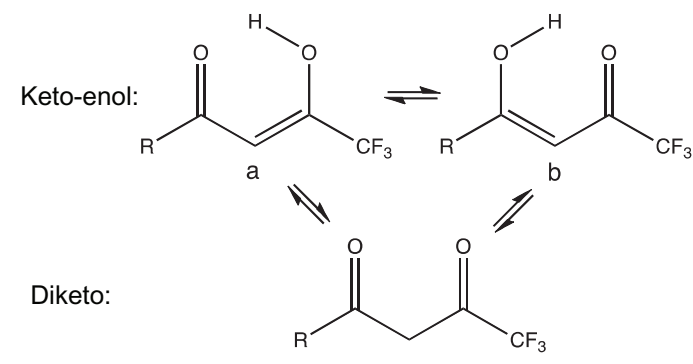

11

$\delta:$

$$
\text { Diketo: -83--80 keto-enol: -78--76 }
$$<smiles>[X]C(=O)/C=C(/O)C(F)(F)F</smiles>

$\mathrm{R}=$ alkyl, aryl

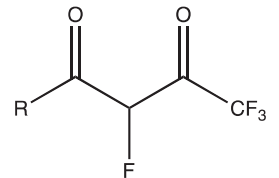

12

Diketo: -83--81

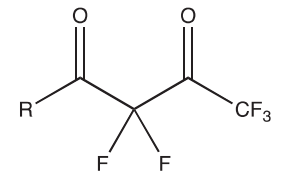

13
Diketo: $-82--81$

$\mathrm{X}=\mathrm{OR}, \mathrm{NH}_{2}, \mathrm{NHR}, \mathrm{NR}_{2}$

Figure 8 Acyclic trifluoromethyl- $\beta$-dicarbonyls.

Abbreviations: $\mathrm{CF}_{3}$, trifluoromethyl; $\mathrm{R}$, alkyl, aryl; $\mathrm{OR}$, alkoxy; $\mathrm{NH}_{2}, \mathrm{NHR}, \mathrm{NR}_{2}$, amino.

\section{Trifluoroacetyl-cycloalkanones}

In cases where the TFA group is attached to a ring system, such as those shown in Figure 9, substrate topological constraints serve to further deshield the $-\mathrm{CF}_{3}$ group relative to the acyclic trifluoromethyl- $\beta$-dicarbonyls discussed earlier. A neat liquid ${ }^{19} \mathrm{~F}$ NMR study of these compounds, conducted by Ebraheem, ${ }^{8}$ helped establish that ring size can modulate chemical shifts and that highly concentrated samples of these compounds shift the keto-enol $\rightleftharpoons$ diketo equilibrium to permit observation of the diketo form.

According to Ebraheem, the ${ }^{19} \mathrm{~F}$ NMR data for compound 15 is indicative of an exocyclic keto-enol form as the major tautomer present (98\%). It is possible that the observed chemical shift value for $15(\delta=-74.95 \mathrm{ppm})$ is partially attributed to the limited flexibility of the smaller cyclopentane ring system. The diketo form (2\%) was also observed for $15(\delta=-80.96 \mathrm{ppm})$. When the ring size is increased from 5 to $6-8$ carbons (compounds 16-18), however, the dominant form is the endocyclic keto-enol $(90.5 \%-93.9 \%)$ with a slightly larger proportion of the diketo form also found in the neat liquids $(6.1 \%-9.5 \%)$. The chemical shifts recorded for compounds 16-18, (keto-enol: $\delta=-71.81$ to $-72.99 \mathrm{ppm}$; diketo: $\delta=-79.90$ to $-80.50 \mathrm{ppm}$ ) are indicative of how substrate topology in larger, more flexible ring systems can cause slight deshielding of the fluorine nucleus.

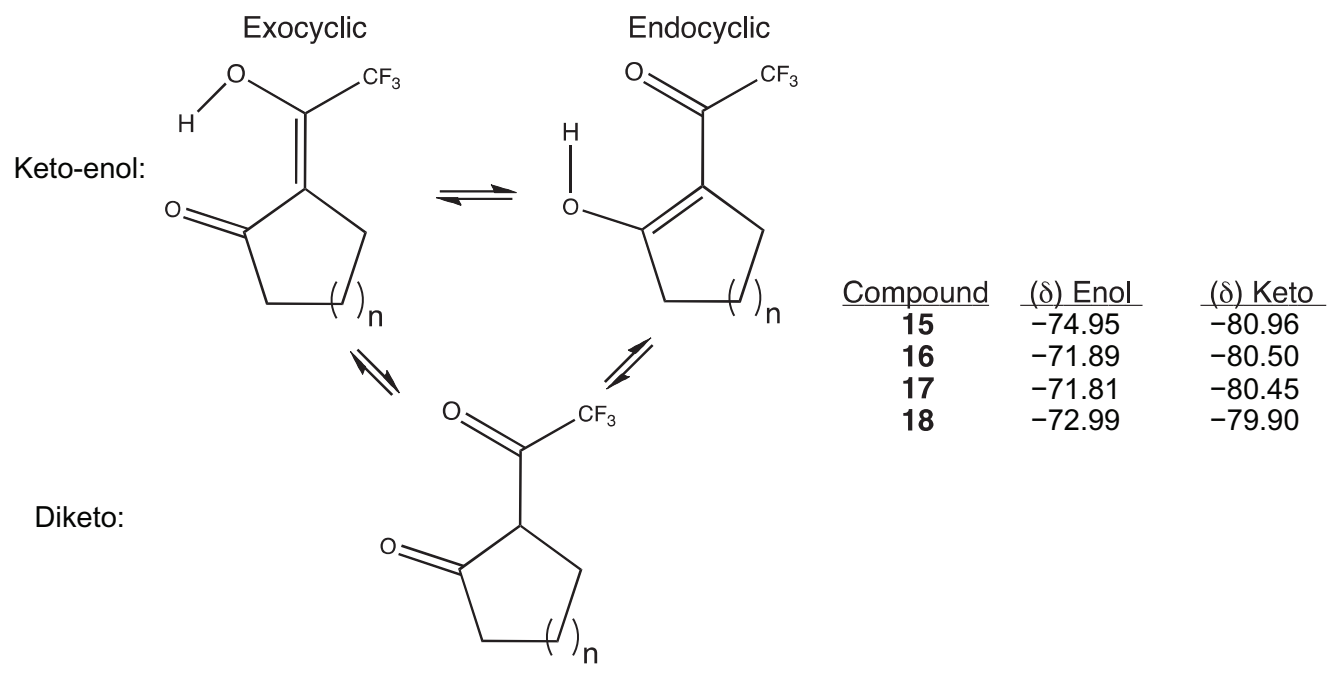

$15(n=1)-18(n=4)$

Figure 9 Trifluoroacetyl-cycloalkanones. 


\section{Fused-ring trifluoroacetylated ketones}

The molecules depicted in Figure 10 are trifluoroacetylated derivatives of indanone and tetralone, fused-ring systems incorporating benzene and five- or six-membered rings, respectively. ${ }^{13,14}$ As in the previous section, the variation of ring size and topology influences the shielding of ${ }^{19} \mathrm{~F}$ NMR resonances for these compounds.

In a dilute solution phase study, Salman found that 2-trifluoroacetyl-1-indanone (19) followed a similar trend observed for compound 15 , namely that the exocyclic keto-enol form was dominant. ${ }^{13}$ Compound 20, 2-trifluoroacetyl-1tetralone, was found to exist as a 1:1 ratio of endocyclic: exocyclic keto-enols. The chemical shifts for 19 and 20 observed in $\mathrm{CDCl}_{3},-73.2 \mathrm{ppm}$ and $-72.1 \mathrm{ppm}$, respectively, reflect the greater deshielding effect on the $\mathrm{CF}_{3}$ group when conjugation is extended. ${ }^{19} \mathrm{~F}$ NMR studies of 19 and 20 in the highly polar aprotic solvent dimethylformamide (DMF) show greater deshielding of the $\mathrm{CF}_{3}$ group relative to $\mathrm{CDCl}_{3}$, in accordance with other solvent-effects studies mentioned earlier. It is interesting to note that the diketo form $(\sim 6 \%)$ was only identified for compound 20 , indicating that the polarity of DMF is sufficient to shift the keto-enol $\rightleftharpoons$ diketo equilibrium slightly for the six-membered ring system. The cyclopentane ring of the indanone (19) may lack the structural flexibility to overcome the keto-enol preference even in highly polar solvents.

In more recent work, compounds 21 and 22 were investigated and found to exist solely as the exocyclic keto-enol and the endocyclic keto-enol forms, respectively. ${ }^{14}$ The higher level of deshielding of the $\mathrm{CF}_{3}$ group in the case of these compounds relative to 19 and 20 is likely due to a combination of substrate topology and the extended conjugation of the keto-enol forms.

Compound 23 is an unusual case, the study of which is ongoing. Initial ${ }^{19} \mathrm{~F}$ NMR spectroscopic results indicate that the molecule exists as the triketone $(\delta=-75.90 \mathrm{ppm})$, while $\mathrm{ab}$ initio computations show the triketone tautomer to be lower in energy by approximately $1 \mathrm{kcal} / \mathrm{mol}$ than either the exocyclic or endocyclic keto-enol tautomers (Sloop et al, unpublished data, 2013). ${ }^{19}$

Compound 24 was found to exist solely as the endocyclic keto-enol tautomer shown. The structure was verified by X-ray crystallography and the ${ }^{19} \mathrm{~F}$ NMR chemical shift observed is consistent with that of other keto-enol tautomeric forms.

In one of the first reported examples of an exocyclic dienol tautomer, compound 25 exhibits a higher degree of deshielding of the $\mathrm{CF}_{3}$ group $(\delta=-68.50 \mathrm{ppm})$, again a consequence of the substrate topology and the extended cross-conjugation noted in this structure. Like 24, the unique keto-enol structure has been corroborated by X-ray crystallography.

\section{$\alpha, \alpha, \alpha$-trifluoromethyl- I,3,5-triketones}

The trifluoromethyl-1,3,5-triketone class of compounds enjoys greater conjugation than $\beta$-diketones owing to the possibility of a variety of keto-enol tautomeric forms that

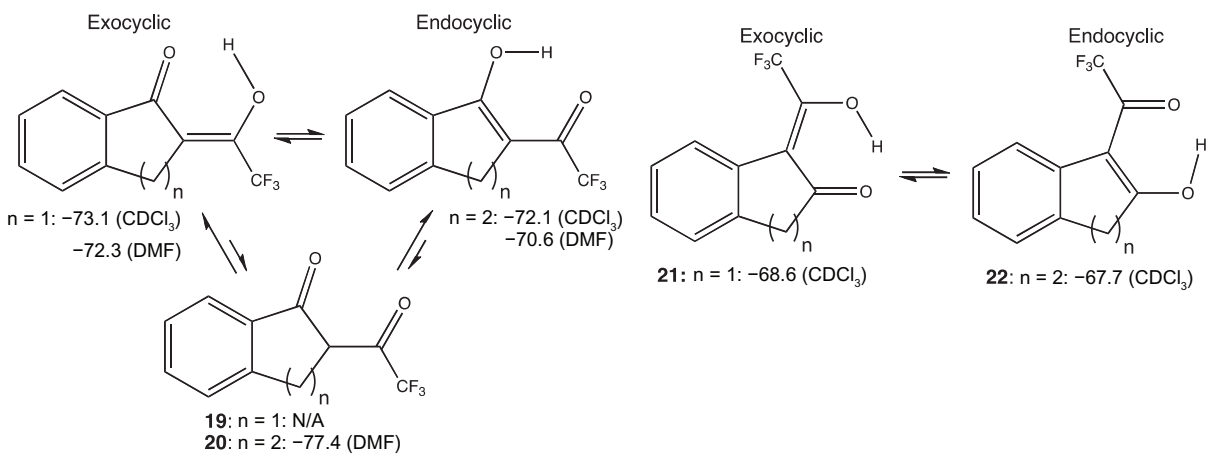

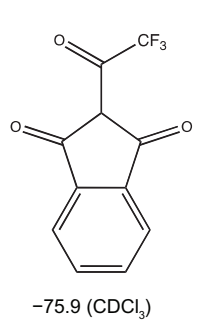

23

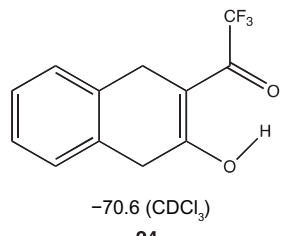

24

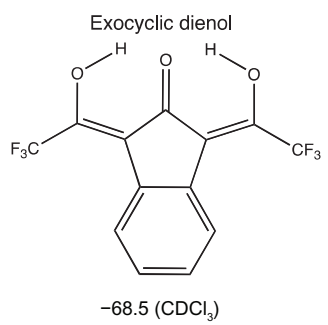

25

Figure 10 Fused-ring trifluoroacetylated ketones.

Abbreviations: $\mathrm{CDCl}_{3}$, deuteriochloroform; DMF, deuteriodimethylformamide. 
could potentially be present. Representative examples are shown in Figure 11.

Compound 26, 1,1,1,7,7,7-hexafluoro-2,4,6heptanetrione, is a simple example of this class of triketone. The observed chemical shift at $\delta=-75.2 \mathrm{ppm}$ as the sole ${ }^{19} \mathrm{~F}$ NMR resonance is fully consistent with the presence of the symmetric, cross-conjugated, dienolic tautomer depicted in Figure $11 .^{20}$

As demonstrated in earlier examples, when an additional ring system is incorporated in the substrate topology, deshielding of the $\mathrm{CF}_{3}$ group increases. Recent studies of compound 27 show the extension of conjugation into the tetralone ring system causes the ${ }^{19} \mathrm{~F}$ NMR resonance to shift upfield slightly by $\sim 3 \mathrm{ppm}$. In this case, the observation of a resonance at $\delta=-72.04 \mathrm{ppm}$ in the ${ }^{19} \mathrm{~F}$ NMR indicates a single, cross-conjugated, dienol tautomer. ${ }^{14}$

This deshielding trend is even more evident in compound 28, where we constrain the topology and electronic effects with the bicyclic, aromatic, naphthol system. ${ }^{14}$ In this instance, the hydroxyl group cannot participate in tautomerization to a ketonic form since that would require loss of aromaticity. The additional aromatic ring system in 28 further deshields the $\mathrm{CF}_{3}$ group, resulting in a shift upfield of $0.4 \mathrm{ppm}$ relative to 27 . Observation of a single ${ }^{19} \mathrm{~F}$ NMR resonance at $\delta=-71.60 \mathrm{ppm}$ is indicative of the characteristic cross-conjugated dienolic tautomer depicted in Figure 11.

\section{Cyclic trifluoroacetylated triketones}

As our examination of cyclic trifluoromethylated $\beta$-diketones has shown, ring systems can modulate ${ }^{19} \mathrm{~F}$ chemical shifts of the $\mathrm{CF}_{3}$ group. For the cyclic trifluoromethylated triketones depicted in Figure 12, the ${ }^{19} \mathrm{~F}$ chemical shifts observed for the $\mathrm{CF}_{3}$ groups align with deshielding effects already discussed.

While compounds 29 and 30 are currently under investigation, preliminary NMR data collected on 29 suggest that the same type of substrate topology effects found in compounds 15,19 , and 21 is in operation - an exocyclic keto-enol form predominates in $\mathrm{CDCl}_{3}$ solution. For compound 30, the endocyclic keto-enol form is substantiated by the ${ }^{19} \mathrm{~F}$ NMR resonance at $\delta=-76.30 \mathrm{ppm}$, a fact consistent with data discussed for compounds 16, 20, and 22. Consistent with previously discussed solvent effects, NMR studies of compounds 29 and 30 in the highly polar DMSO further deshield the $\mathrm{CF}_{3}$ group by $\sim 2 \mathrm{ppm} .{ }^{19}$

Sevenard et al prepared and studied compound 31 . Based on a combination of ${ }^{1} \mathrm{H},{ }^{13} \mathrm{C}$, and ${ }^{19} \mathrm{~F}$ NMR data, they concluded that an 80:20 equilibrium exists between the exocyclic dienol and the endocyclic keto-enolic structures in the nonpolar solvent $\mathrm{C}_{6} \mathrm{~F}_{6}{ }^{21} \mathrm{~A}$ thorough review of the literature has revealed no other examples of a cyclohexanone-based bis-exocyclic enol tautomer. The most interesting finding in this study was that the exocyclic dienol was present in a larger proportion than the endocyclic tautomer, an observation that has not been supported previously in the literature for trifluoroacetylated cyclohexanones. Clearly, however, the observation of distinct ${ }^{19} \mathrm{~F}$ NMR resonances for each type of $-\mathrm{CF}_{3}$ group found in the tautomeric mixture as well as the chemical shift positions support the presence of the two separate keto-enol tautomers.

\section{Trifluoroacetylated aromatics}

As discussed earlier, extended conjugation tends to deshield the ${ }^{19} \mathrm{~F}$ NMR resonance of the TFA group. When a TFA group is attached directly to an aromatic ring system, the $-\mathrm{CF}_{3}{ }^{19} \mathrm{~F}$ NMR resonance is shifted upfield relative to nonconjugated, alkyl-substituted, trifluoroacetylated species, a consequence of deshielding. Examples of aromatics containing the TFA functionality are shown in Figure 13.

For compound 32, the topology of the aromatic ring system "locks" the TFA group into a keto-enol form that cannot tautomerize. The presence of the carbonyl adjacent to the $-\mathrm{CF}_{3}$ group and the ortho-substituted hydroxyl group that hydrogen bonds with the carbonyl combine effects for $a^{19} \mathrm{~F}$ NMR resonance that is slightly more shielded than the other examples in our series.
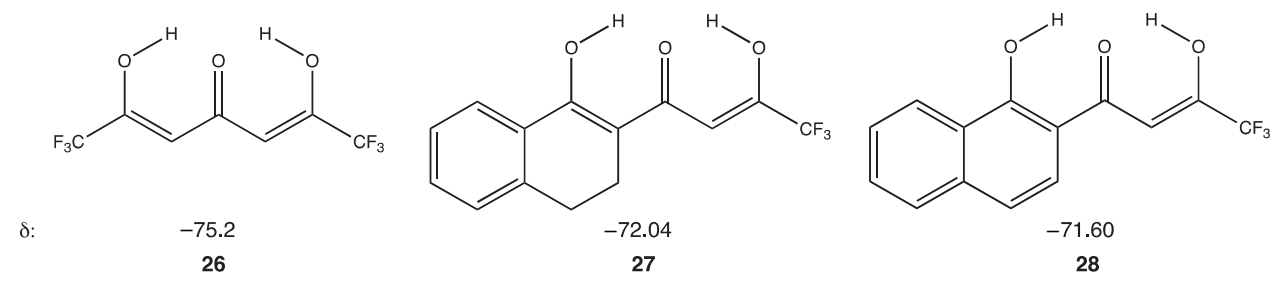

Figure I I $\alpha, \alpha, \alpha$-Trifluoromethyl- I,3,5-triketones. Abbreviation: $\mathrm{CF}_{3}$, trifluoromethyl. 


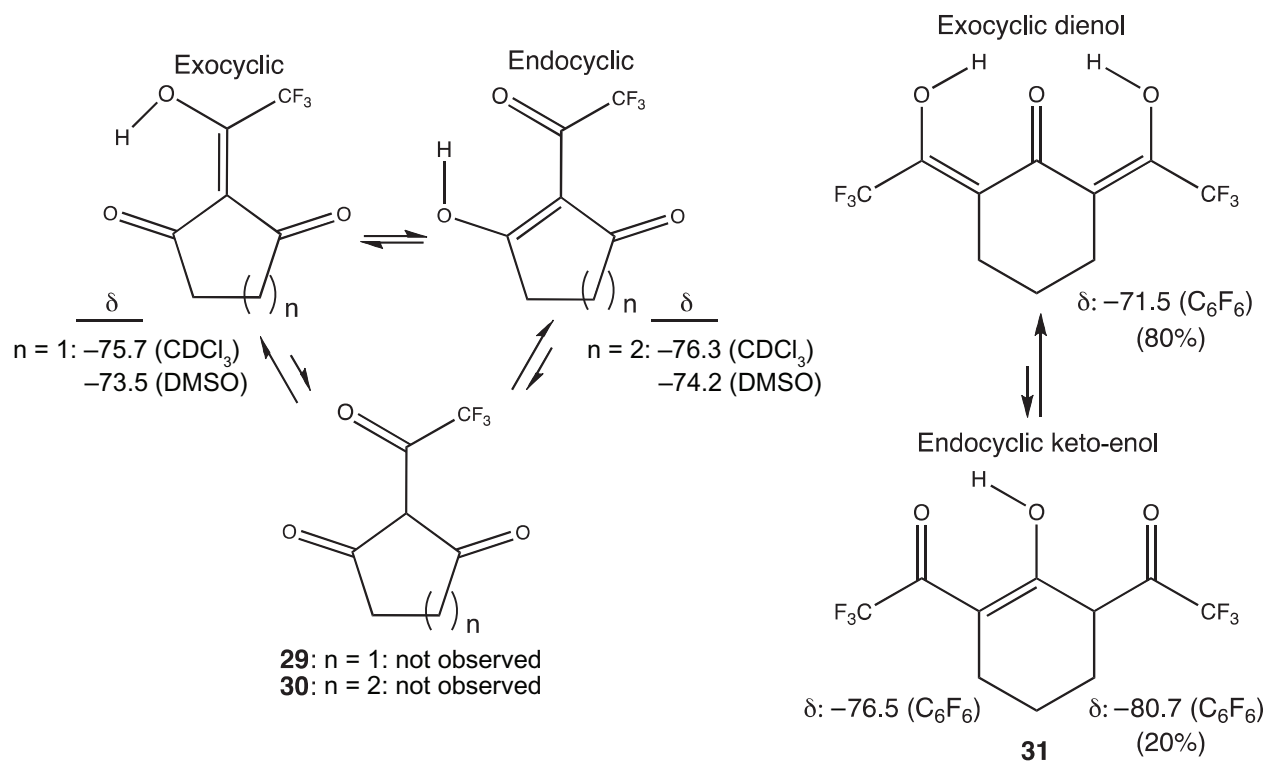

Figure 12 Cyclic trifluoroacetylated triketones.

Abbreviations: $\mathrm{CF}_{3}$, trifluoromethyl; DMSO, dimethyl sulfoxide; $\mathrm{CDCl}_{3}$, deuteriochloroform; $\mathrm{C}_{6} \mathrm{~F}_{6}$, hexafluorobenzene.

Compound series 33, prepared and studied by Maekawa et al, demonstrate that the ${ }^{19} \mathrm{~F}$ NMR chemicals shifts vary little for substituted $(\mathrm{R}=$ alkyl, aryl) trifluoroacetophenone derivatives. ${ }^{22}$ Therefore, the principal deshielding effect observed in this series is governed by the direct attachment of the benzene ring to the TFA group.

Compound 34 is an unusual example of a steric-structural topology deshielding effect on the ${ }^{19} \mathrm{~F} \mathrm{NMR}-\mathrm{CF}_{3}$ chemical shift. ${ }^{10}$ The $-\mathrm{CF}_{3}$ groups in the $2,2^{\prime}$-bis(trifluoroacetyl) biphenyl structure are evidently close enough in proximity to the biphenyl ring system to allow for greater deshielding of the fluorine nuclei than would normally occur. ${ }^{23}$

\section{Trifluoroacetylated heterocycles}

Trifluoroacetylated heterocyclic compounds comprise a very important class of molecules, serving as synthons for natural products and numerous combinatorial processes important to the general chemical industry as well as the pharmaceutical and agrochemical industries. ${ }^{24}$ For the purposes of this review, we will limit our scope to heterocyclic molecules containing nitrogen and oxygen. Some representative examples are shown in Figure 14.

Fused bicyclic ring system examples include nitrogencontaining indole and benzotriazole derivatives $35-37 .^{25-27}$ The nonaromatic heterobicyclic compound 35 has conjugation limited to the heterocyclic ring, resulting in a greater level of $-\mathrm{CF}_{3}$ group shielding $(\delta=-74.3 \mathrm{ppm})$ than that found for the heteroaromatic indole $36(\delta=-73.4 \mathrm{ppm})$. The attachment of the TFA group on the heteroatom coupled with the aromaticity of the bicyclic ring system in compound 37 creates the largest deshielding of the $-\mathrm{CF}_{3}$ group, causing an upfield shift of the ${ }^{19} \mathrm{~F}$ resonance of more than $3 \mathrm{ppm}$.

Single ring systems examined in this review include the pyridine, pyrrole, and pyrazole classes of heterocycles. ${ }^{27-29}$ The heteroaromatic nature of compound 38 ,<smiles>O=C(c1cc2ccccc2cc1O)C(F)(F)F</smiles>

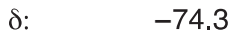

32<smiles>[R]c1ccc(C(=O)C(F)(F)F)cc1</smiles>

$-72.8-7.51$

33

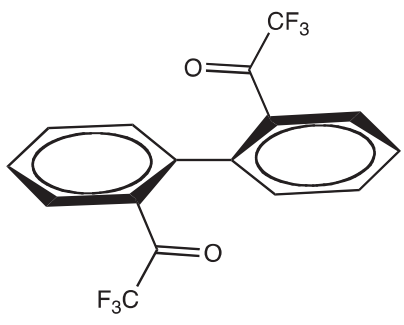

$-67.7$

34

Figure 13 Trifluoroacetylated aromatics.

Abbreviations: $\mathrm{CF}_{3}$, trifluoromethyl; $\mathrm{R}$, hydrogen, alkyl, acyl. 


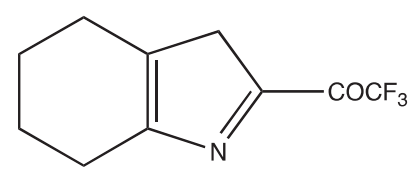

$\delta:$

$$
-74.3
$$

35

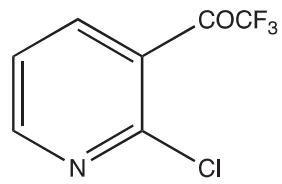

$-73.4$

$\delta:$

38

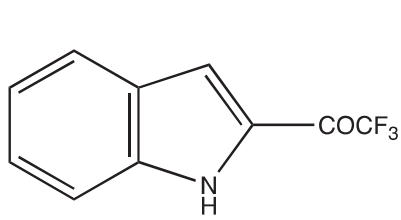

$-73.4$

36

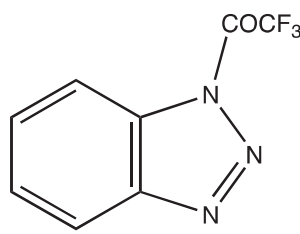

$-70.1$

37

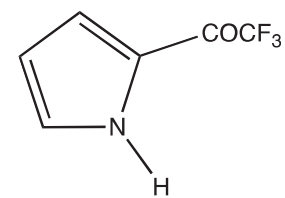

$-72.6$

39

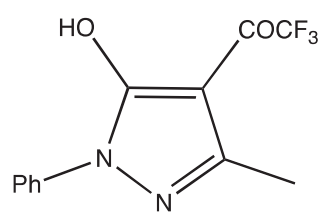

$-71.0$

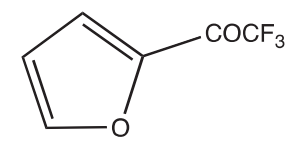

$-73.7$

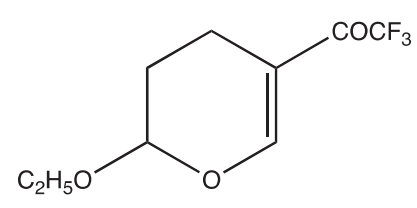

$-68.5$

42

Figure 14 Trifluoroacetylated heterocycles.

2-chloro-3-trifluoroacetylpyridine, deshields the $-\mathrm{CF}_{3}$ group $(\delta=-73.4 \mathrm{ppm})$ to a lesser extent than the TFA-substituted benzenes (compound series 33 ) discussed earlier. ${ }^{19} \mathrm{~F}$ chemical shifts for the trifluoroacetylated pyrrole 39 and pyrazole 40 indicate a greater deshielding effect than found in 38 , possibly a consequence of the reduction in ring size.

The oxygen-containing 2-trifluoroacetylfuran (41) ${ }^{19} \mathrm{~F}$ chemical shift is similar to those of the pyrrole and indole compounds. ${ }^{30}$ The five-membered heteroaromatic ring systems evidently give rise to similar electronic effects on the $\mathrm{CF}_{3}$ group. The upfield ${ }^{19} \mathrm{~F}$ chemical shift $(\sim 3 \mathrm{ppm})$ of the nonaromatic dihydropyran derivative (42), which is more highly deshielded than the other heterocycles in this group, may be rationalized using resonance theory as shown in Figure 15. The extension of conjugation by delocalization of electron density in the resonance contributor may, in part, account for the observed upfield chemical shift observed in this case.<smiles>COC1CCC(C(=O)C2CCCC2)C(OC)C1</smiles>

Figure 15 Resonance deshielding of $-\mathrm{CF}_{3}$ in pyran 42 . Abbreviations: ' $\mathrm{CF}_{3}$, trifluoromethyl.

\section{Conclusion}

This review of nine major classes of TFA-containing molecules provides new comparisons of how ${ }^{19} \mathrm{~F}$ NMR may be utilized in structural connectivity analyses of these fluorinated species. While the ${ }^{19} \mathrm{~F}$ NMR chemical shifts for the $-\mathrm{COCF}_{3}$ groups in this study range from approximately $-85 \mathrm{ppm}$ for the parent hexafluoroacetone to $-67 \mathrm{ppm}$ for certain TFA-bearing aromatics, the narrow band of variability can nonetheless yield valuable information to aid in understanding the structural topology, electronic environment, solvent, and concentration effects that are often examined by NMR spectroscopy.

The chemical shift variability observed for the $-\mathrm{COCF}_{3}$ group results from the interplay of substrate structure, electronic environment, solvent polarity, and in a few important instances, concentration. Key structure-related influences include constraints imposed by the introduction of ring systems. Structural, electronic, and solvent effects can conspire to change tautomeric equilibria in TFA-substituted di- and triketones, producing enolic and keto forms for which the chemical shifts can vary from $-82 \mathrm{ppm}$ to $-68 \mathrm{ppm}$ $\left(\Delta \delta_{\mathrm{F}}=\sim 16 \mathrm{ppm}\right)$. Steric deshielding of fluorine, like that found in 2,2'-ditrifluoroacetylbiphenyl, is a phenomenon that occurs when large groups in close proximity to one another disturb the p orbital electrons of the fluorine atom.

Distinct electronic effects arising from neighboring groups, conjugation, and resonance can also have substantial 
deshielding effects on the $-\mathrm{COCF}_{3}$ group. The presence of a multiple bond in conjugation with the TFA group produces a $\Delta \delta_{\mathrm{F}}=\sim 7 \mathrm{ppm}$, while incorporation of an aromatic system conjugated with the TFA can extend the chemical shift range another $6 \mathrm{ppm}$. Heteroatoms present in carboxylic acids have a deshielding effect of similar magnitude brought about by resonance, often resulting in a $\Delta \delta_{\mathrm{F}}=\sim 7 \mathrm{ppm}$.

Solvent effects on the ${ }^{19} \mathrm{~F}$ chemical shift of the $-\mathrm{COCF}_{3}$ group are normally $<2 \mathrm{ppm}$, unless solvent polarity leads to a shift in tautomeric equilibria. Highly polar solvents cause an upfield shift of the $-\mathrm{CF}_{3}{ }^{19} \mathrm{~F}$ NMR resonance. In cases where keto-enol $\rightleftharpoons$ diketo or keto-enol $\rightleftharpoons$ triketo equilibria are modulated by solvent polarity (as in the case of TFA-substituted $\beta$-diketones where the proportion of the diketo form increases with highly polar solvents), $\Delta \delta_{\mathrm{F}}$ can range from $\sim 5-9 \mathrm{ppm}$.

The concentration of TFA-bearing $\beta$-diketones in solution can also influence the proportions of tautomers present. In dilute solutions the keto-enol tautomer is usually the only discernible species present, while the diketo form proportion can increase to $\sim 10 \%$ of the mixture composition in neat solutions of the $\beta$-diketone.

\section{Acknowledgments}

The author thanks the School of Science and Technology at Georgia Gwinnett College and the United States Military Academy for their support of this work.

\section{Disclosure}

The author reports no conflicts of interest in this work.

\section{References}

1. Nauta WT, Rekker RF, editors. Biological Activities of 1,3-Indandiones. Pharmacochemistry of 1,3-Indanediones. New York: Elsevier Scientific Publishing Co; 1981:87-269.

2. Wiesner S, Springer E, Sasson Y, Almog J. Chemical development of latent fingerprints: 1,2-indanedione has come of age. $J$ For Sciences. 2001;46(5):1082-1084.

3. Daehne S, Resch-Genger U, Wolfbeis OS, editors. Proceedings of the NATO Advanced Research Workshop on Syntheses, Optical Properties and Applications of Near Infrared (NIR) Dyes in High Technology Fields. Dordrecht: Kluwer Academic Publishers; 1997;52:363-364.

4. van Klink JW, Larsen L, Perry NB, et al. Triketones active against antibiotic-resistant bacteria: synthesis, structure-activity relationships, and mode of action. Bioorg Med Chem. 2005;13:6651-6662.

5. An TY, Hu LH, Chen RM, Chen ZL, Li J, Shen Q. Anti-diabetes agents -1 . Tetralone derivative from Juglans regia. Chin Chem Lett. 2003;14(5):489-490.

6. Jain R, Jain SC, Arora RA. New cholestane derivative of Abutilon bidentatum Hochst and its bioactivity. Pharmazie. 1996;51(4):253-254.

7. Mentré F, Pousset F, Comets E, et al. Population pharmacokineticpharmacodynamic analysis of fluindone in patients. Clin Pharmacol Ther. 1998;63:64-78.

8. Ebraheem K. ${ }^{1} \mathrm{H},{ }^{13} \mathrm{C}$ and ${ }^{19} \mathrm{~F}$ NMR studies on the structure of the intramolecularly hydrogen bonded cis-enols of 2-trifluoroacetylcycloalkanones. Monatshefte fur Chemie. 1991;122:157-163.
9. Sloop J, Bumgardner CL, Washington G, Loehle WD, Sankar SS, Lewis AB. Keto-enol and enol-enol tautomerism in trifluoromethyl- $\beta$ Diketones. J Fluorine Chem. 2006;127:780-786.

10. Dolbier W. Guide to Fluorine NMR for Organic Chemists. Hoboken: John Wiley and Sons, Inc; 2009;9-15,137-176.

11. Forsen $\mathrm{S}$, Nilsson M. Proton magnetic resonance studies of enolised B-triketones. Acta Chem Scand. 1959;13:1383-1394.

12. Sloop J, Boyle PD, Fountain AW, Pearman WF, Swann JA. Electron deficient aryl $\beta$-diketones: synthesis and novel tautomeric preferences. Eur J Org Chem. 2011;5:936-941.

13. Salman S. Multinuclear magnetic resonance study of tautomerism in fluorinated $\beta$-diketones. Magn Reson Chem. 1990;28:645-650.

14. Sloop J, Boyle PD, Fountain AW, et al. Novel fluorinated indanone, tetralone and naphthone derivatives: synthesis and unique structural features. Appl Sci Special Edition: Organo-Fluorine Chemical Science. 2012;2:61-99.

15. Reichardt C. Solvents and Solvent Effects in Organic Chemistry, 3rd ed. Weinheim: Wiley-VCH Verlag GmbH and Co KGaA; 2003; 107 : 329-362,375-388.

16. Gerig J. Fluorine NMR. Monograph published online. Available from http://www.biophysics.org/portals/1/pdfs/education/gerig.pdf. 2001:1-35. Accessed November 17, 2012.

17. Kondratov I, Gerus II, Kacharov AD, Gorbunova MG, Kukhar VP, Fröhlich R. New derivatives of trifluoroacetyl acetaldehyde and trifluoroaldol. J Fluorine Chem. 2005;126:543-550.

18. Bumgardner C, Whangbo M. Secondary orbital effects in fluorine compounds. In: Liebman J, Greenberg A, Dolbier W, editors. Fluorine-Containing Molecules, Structure, Reactivity, Synthesis and Applications. New York: VCH Publishers; 1988:88-91.

19. Sloop J, Bumgardner CL, Loehle WD. Synthesis of fluorinated heterocycles. J Fluorine Chem. 2002;118:135-147.

20. Sevenard DV, Kazakovaa O, Chizhovc DL, Röschenthalera GV. Synthesis of 1,1,1,7,7,7-hexafluoroheptane-2,4,6-trione, the simplest fluorinated 1,3,5-triketone. J Fluorine Chem. 2006;127:983-986.

21. Sevenard D, Khomutov OG, Kodess MI, Pashkevich KI. Synthesis and tautomeric equilibrium of 2,6- bis(trifluoroacetyl) cyclohexanone. Russ Chem Bull. 1999;48(2):400-401.

22. Maekawa H, Ozaki T, Zulkeflee D, Murakami T, Kihara S, Nishiguchi I. Abnormal and direct para-trifluoroacetylation of branched alkyl phenyl ketones by Mg-promoted reductive aromatic substitution. Synlett. 2012;3:401-404.

23. Sloop J. Selective incorporation of fluorine in heterocyclic molecules. In: Gardner I, editor. Fluorine Chemistry Research Advances. New York: Nova Science Publishers, Inc; 2007:1-34.

24. Hasegawa T, Omote M, Sato K, Ando A, Kumadaki I. New approach to a novel axially chiral ligand showing spontaneous enrichment of axial chirality. Chem Pharm Bull. 2003;51(3):265-267.

25. Sigana AL, Guseva DV, Chkanikova ND, Shmidtb EY, Ivanovb AV, Mihalevab AI. Hydroxyalkylation of 4,5,6,7-tetrahydroindole with polyfluorocarbonyl compounds as a route to 2 -substituted indoles. Tetrahedron Lett. 2011;52:5025-5028.

26. Katritsky A, et al. (Trifluoroacetyl)benzotriazole: a convenient trifluoroacetylating reagent. J Org Chem. 1997;62(3):726-728.

27. Peláez W, Burgos Paci MA, Argüello GA. A closer insight into the mechanism operating in the trifluoroacetylation of pyrrole. The new trifluoromethyl pirroylmethane discovered. Tetrahedron Lett. 2009;50(17):1934-1938.

28. Uzoukwu B, Adiakwu P. Spectroscopic studies of Th(IV), La(III) and $\mathrm{Pb}$ (II) complexes of 4-trifluoroacetyl and 4-trichloroacetyl derivatives of 3-methyl-1-phenylpyrazol-3-one. J Natn Sci Coun Sri Lanka. 1996;24(3):221-225.

29. Kremleva MM, Mushtaa AI, Tyrrab W, Naumannb D, Fischerb HTM, Yagupolskiia YL. Silver compounds in synthetic chemistry part 5: selective syntheses of trifluoromethylketones, $\mathrm{RCOCF}_{3}$, from trifluoromethylsilver, $\mathrm{AgCF}_{3}$, and corresponding acyl chlorides, $\mathrm{RCOCl}$. J Fluorine Chem. 2007;128:1385-1389.

30. Zhu S, Jin G, Peng W, Huang Q. Cycloaddition reactions of $\beta$-trifluoroacetylvinyl ethers. Tetrahedron. 2003;59:2899-2905. 
Reports in Organic Chemistry

Dovepress

\section{Publish your work in this journal}

Reports in Organic Chemistry is an international, peer-reviewed, open access journal publishing original research, reports,

Visit http://www.dovepress.com/testimonials.php to read real quotes reviews and commentaries on all areas of organic chemistry. The manuscript management system is completely online and includes a very quick and fair peer-review system, which is all easy to use. from published authors.

Submit your manuscript here: http://www.dovepress.com/reports-in-organic-chemistry-journal 